\title{
Die Tätigkeit der Fürsorgestellen für Lungenkranke in Bayern.
}

\author{
Berichtigung. \\ Von \\ Medizinalrat Dr. G. Seiffert.
}

In dem Aufsatz über „,die Tätigkeit der Fürsorgestellen für Lungenkranke in Bayern" Bd. 55, Heft 2, S. 18 oben wurden in der Tabelle über die Zahl der gemeldeten Tuberkulosesterbefälle aus Versehen teilweise für eine andere Tabelle gültige Zahlen wiedergegeben. Die Tabelle muß lauten:

$\begin{array}{lccc} & \text { Sterbefalle } & \text { gemeldete Fälle } & \text { in } \% \\ \text { Bayern insgesamt . . . } & \mathbf{1 1 , 1 1 1} & \mathbf{5 , 6 6 9} & \mathbf{5 1} \\ \text { Stadt . . . . . . . . . } & \mathbf{3 , 9 4 4} & \mathbf{3 , 2 2 3} & \mathbf{8 4} \\ \text { Land . . . . . . . . } & \mathbf{7 , 1 6 7} & \mathbf{2 , 4 4 6} & \mathbf{3 4}\end{array}$

Mit dieser Änderung entspricht die Tabelle der graphischen Darstellung Abb. 15. 